\title{
Optimization potential of the Digital Transformation program in EU top transportation company
}

\author{
Aleksandrs Popovs ${ }^{1,}$ and Zane Drinke ${ }^{1}$ \\ ${ }^{1}$ Turiba University Faculty of Business Administration, 68 Graudu Street, Riga, LV-1058, Latvia
}

\begin{abstract}
Research background: We are living in complex and uncertain times and nowadays no one is doubting the DT expediency in order to support business transformation process or to boost agility for the new reality adoption and coping with the Crisis

Purpose of the article: The aim of this study was to explore and assess Digital Transformation journey by one of Europe's largest transport companies - Girteka Logistics, in change environment and under uncertainty. The study collects data from the company's Digital Transformation program, enabled by SAP solutions, insides from the Digital Transformation program internal and external teams.

Methods: Within the study empirical research with descriptive research method was carried out using qualitative and quantitative observation methods. As the study is only about one company, the statistical population represents most of the Digital Transformation program team members. The data collection happened by the online questionary and afterward through the interviews with the key respondents to validate and extend gathered data. Second part of the data gathered is from Girteka's Digital Transformation program documentation. The data collection happened by the documentation analysis and information consolidation.

Findings \& Value added: As the result of the study the antifragile generic hand-on Digital Transformation program roadmap was created and number of aspects were highlighted to be considered for the potential future research, like internal transformation team competency level requirements, expert labor marker and transformation partners situation as enabler for the companies' digital transformation, process for the digital transformation program and overall business KPI definition to be used as transformation execution success indicator.
\end{abstract}

Keywords: Digital Transformation; Readiness for Change; Girteka; SAP

JEL Classification: $M 10 ; M 15 ; O 33$

\footnotetext{
* Corresponding author: aleksandrspov@gmail.com
} 


\section{Introduction}

The aim of this study was to explore and assess Digital Transformations (hereinafter - DT) journey by one of Europe's largest transport companies - Girteka Logistics and affiliate companies (hereinafter - Girteka), in change environment and under uncertainty circumstances (hereinafter possible use of notation - Crisis). Girteka Logistics is Europe's leading asset-based transport company running massive DT together with exponential business grow also during COVID-19 Crisis.

Research of the still on-going DT journey of the Girteka allows to define potential optimized (or in other words - antifragile) generic hand-on DT program roadmap for the companies initiating such transformations.

\subsection{Digital Transformation}

We are living in complex and uncertain times (Sharma et al., 2020, Otero, 2020) and nowadays no one is doubting the DT expediency in order to support business transformation process or to boost agility for the new reality adoption and coping with the Crisis. The challenges around the Crisis (meaning COVID-19) have further spurred organizations into action by increasing their awareness of the need to accelerate DT (McKinsey, 2020).

Companies who are executing DT and operating in open-minded and agile way ensure increase of their speed of adoption to the changing world (Aghina et al., 2017, Dingsøyr, T, 2012). Also, there is clearly trackable the rise in interest of this topic referring the DT literature research. The number of publications around DT rapidly growing year over year (Hanelta et al., 2021).

By saying this, let's give a definition of the DT in the new reality - DT as organizational change triggered and shaped by the widespread diffusion of digital technology and urge to adopt to the constantly changing environment addressing uncertainty. DT be classified as continuous change that can be triggered and shaped by episodic bursts, while the latter are inducing further continuous change (Wessel et al., 2021), however DT program should have defined timeline to be able to ensure that business transformation goals defined for the DT program will be reached.

The wide spread of digital technologies across societies renders DT a strategic imperative for a business transformation across number of companies (Verhoef et al., 2021) and Girteka is not an exception.

\subsection{About the Girteka and DT Program}

Girteka based in the city of Vilnius, Lithuania. Founded in 1996. Today, it is one of Europe's largest transport companies. The company delivers more than 800,000 full truck loads annually and grew organically from 600 trucks in 2010 to more than 7,800 trucks and 7,600 trailers operating in Europe, Scandinavia, and CIS. (Girteka, 2021).

To cope with the Crisis (COVID-19) a wide range of professionals were mobilized including supply chain personal, like truck drivers, warehouse workers, and logistical staff who keep delivering food, medical supplies, medicine, and other essentials (Forbes, 2020) where Girteka was directly involved. To be able to ensure effective transportation channels and efficient supply chains also during the Crisis certain actions needed to take place, such ar DT initiation.

Europe's trucking industry is old-fashioned and highly fragmented. Over $90 \%$ of companies operate less than 10 trucks, while only 1\% operate more than 50 trucks (Girteka, 2020). In order to achieve its ambitious vision to become the first European company with 10,000 of its own trucks, Girteka beside the business initiatives has decided to empower the 
company's long-term strategy for success with the execution of DT program supported by SAP digital solutions. SAP company is a trusted DT advisor and $85 \%$ of the transportation and logistics providers in Forbes 2000 are SAP customers, and more than $50 \%$ of the world's packages are shipped by SAP customers using SAP digital solutions. (SAP, 2020)

Digital technology is the foundation for everything the company does from business operations to becoming more sustainable. Having business technology platform, fully integrated and automated systems and processes will not only relieve the workforce of repetitive tasks and free them up to gain real-time control of operations but also will enable data-driven managerial decision with no delay. (Girteka, 2020).

To achieve the company's ambitious business goal and reshape a traditional industry, Girteka is moving ahead with DT program to digitize entire business to scale growth. To ensure that DT will lead to the above-described situation it should be bulletproof and agile to have high resilience to stress factors caused by the Crisis, in other words - antifragile or at least robust DT program need to be in place.

Antifragility in particular case represents the ability to gain from Crisis and disorder. Antifragile is the concept of gaining value from exposure to stressors. (Ramezani, Camarinha-Matos, 2020).

Companies, who got thru the basic DT usually have majority of the end-to-end business processes digitalized and under the full control. The next level of transformation enables to utilize the edge technology benefits, so the companies applying advanced technologies and best practices what helps them to be more resilient, profitable, and sustainable. Those companies are pulling and staying ahead in their industry (SAP, 2021).

This is the strategically expected operational model of Girteka what potentially can be ensured by the DT program realization.

\section{Methodology}

Market demand for digital products and services during the Crisis empowers new forms of business execution and strengthen of competition, therefore DT happening initiated to address the Crisis creates time pressures, but also additional stress to the company.

Having a central process leader for such transformations in the organization might help firms to accelerate their digital transformation and mitigate the stress factors (Firka et al., 2021). Usually, the leader how is managing DT and coping it related activities, and consequences, is the C-suite level employee. It can be the Chief Digital Officer (CDO) (Kunisch et al., 2020), or dedicated DT program lead, like it was set-up in Girteka company. DT lead focus emerging tasks at the top of a company's strategic agenda and activate key stakeholders for their execution (Singh et al., 2020).

The study collects data from the Girteka's DT lead and DT managers and advisors who are directly involved in program initiation and execution.

Within the study empirical research with descriptive research method was carried out using qualitative and quantitative observation methods.

As a first part of the research the online survey and interviews were used as a research method for collecting data from a pre-defined group of respondents to gain information and insights on DT program in Girteka.

There were created 2 surveys using different approaches and tools and were distributed within dedicated DT program team members. One type of the survey was distributed only for one person.

First survey has 30 questions: 1 general questions about the respondent; 17 open-ended questions on the DT program compelling event, scope, timeline, program KPIs, program core and extended team, external advisory scope etc.; and 12 close-ended questions with multiple 
selection option on the DT priorities, correlation between DT program and business strategy and operational activities, company Digital maturity etc.

Second survey has 14 questions: 4 general questions about the respondent, 3 open-ended questions on the DT program definition, program KPIs, COVID-19 effect on the program; 7 close-ended questions with matrix and multiple chose options, prioritization definition option etc. On the DT program compelling event, scope, key stakeholders, expected outcomes, company employees learning curve on Digital topics etc.

The statistical population of this study was above mentioned DT team consisted of 10 experts. The sampling method was based on the study author's previously identified scope of responsibilities of each team member, i.e., there were selected respondents who can give comprehensive view on the DT program and more complete information, i.e., for the study at this stage there was not needed to apply Cochran's formula sample size determination logic due to the number of objective aspects. Sample size was 6 respondents.

After surveys data consolidation and analysis, interviews with the key respondents were deducted to extend the gathered information and validate gathered data. Interviews were deducted with 3 respondents separately.

There was used semi-structured interview approach, i.e., interview as a quantitative research method where a set of prepared closed-ended questions were asked. The interview schedule had a standardized format, the same questions were asked to each interviewee in the same order. Unstructured part of the interview was used to ask open-ended questions and execute the interview more like natural conversation flow. The questions were modified along the interview to suit the respondent's specific experience.

The information gathered during the interviews was qualified, cleared from the noise, structured, and consolidated with the results from the earlier launched surveys.

Second part of the research was based on Girteka's DT program documentation created by the DT team members, business process owners, external DT advisors and system integrators. The data collection happened by the documentation analysis and information consolidation.

The documentation analysis process was structured that way, to have research question defined initially, then analyzing text to define what information intersections are important, what patterns are available. There were analyzed more than 20 documents directly created within and for the DT program.

\section{Results and Discussion}

As DT program is tightly related to the company business strategy, i.e., it's a part of organizations change towards defined goals, the initial DT program was created based on number of aspects and has been started at the beginning of 2020. At the moment the DT program is implemented by $15 \%$ from the defined scope. Timeline for the program is 5 years.

To be able to create initial DT program roadmap the business needs, compelling events, and the main driving factors:

- Customer needs/wants, like send e-orders, receive e-invoices, real-time order status monitoring etc. The consequences of such needs are to be the first choice for the customers. Moreover, some customers are pushing to meet high standards and without DT it's impossible to achieve.

- Business target to become among Top 10 leading European logistic companies, so this raising the necessity to have mature business processes and innovative technologies and tools that could support growth and scalability targets.

- Market trends in logistics industry, like 360-degree view of customer, Customer Experience, full end-to-end visibility to minor details in real-time, AI and robotics 
to automation use in business processes, data insight-driven changes and decisions, timely business opportunities with velocity (accuracy and speed) etc.

- Outdated Core Technology platform.

Girteka has defined the vision for the DT program - 'Set the right foundation to drive capabilities fundamental to Modern Girteka Logistics Business and Technology Strategy'

The DT program initially was created reflecting required activities from the pre-program (preparation) phase, program management and delivery phases. Summary of the activities can be found in the Table 1 - Girteka DT program phases.

Table 1. Girteka DT program phases.

\begin{tabular}{|c|c|c|}
\hline \multicolumn{3}{|c|}{ Preparation phase } \\
\hline $\begin{array}{c}\text { High-level vision } \\
\text { definition }\end{array}$ & Roadmap design and scoping & Program organizational design definition \\
\hline $\begin{array}{ll}\text { - } & \text { Vision definition } \\
\text { - } & \text { Strategy } \\
& \text { definition } \\
\text { - } & \text { High-level DT } \\
\text { program } \\
\text { roadmap } \\
\text { creation }\end{array}$ & $\begin{array}{l}\text { - Strategic portfolio setup } \\
\text { - Related projects scope definition } \\
\text { - Detailed preparation activity plan } \\
\text { creation } \\
\text { - Vendor engagement } \\
\text { - Definition of the DT program scope } \\
\text { - Roadmap design }\end{array}$ & $\begin{array}{l}\text { - Definition of the DT program } \\
\text { operational model } \\
\text { - Definition of the DT program structure } \\
\text { and governance model } \\
\text { - DT program budgeting and budget } \\
\text { control methods implementation } \\
\text { - Definition of the DT program structure }\end{array}$ \\
\hline \multicolumn{3}{|c|}{ Program management phase } \\
\hline \multicolumn{2}{|c|}{ Program setup } & Program management \\
\hline \multicolumn{2}{|c|}{$\begin{array}{l}\text { - DT program management and execution team onboarding and } \\
\text { mobilization } \\
\text { - DT program external advisory and software vendor onboarding } \\
\text { - } \text { Business architecture and IT landscape strategy design }\end{array}$} & $\begin{array}{l}\text { - Project Delivery assurance } \\
\text { - Program execution supporting } \\
\text { activities }\end{array}$ \\
\hline \multicolumn{3}{|c|}{$\begin{array}{c} \\
\text { Delivery phase } \\
\end{array}$} \\
\hline
\end{tabular}

To be able to start the DT program, the high-level consolidated roadmap was created based on 4 questions (what? how? who? when?). Question 'WHAT?' gives the definition of expected outcomes from the DT program, like what Girteka is planning to achieve with DT; question 'HOW' incorporates various topics such as program scope, program realization strategy and tasks, DT progress measurements etc.; question 'WHO?' is about the program and related projects governance model, about the external forces involvement and internal forces maturity; question 'WHEN?' used to define the timeline of the program and related projects.

Considering that the Crisis has direct effect on the DT program, it's impossible to hardcode the setup of the program, therefore agile components need to be embedded in the program. This kind of agility was ensured by the granular implementation of the DT program, starting with one business area what was defines as most critical and urgent subject for transformation, and it was a core business area - transportation management and execution. With this the 'big-bang' DT program implementation approach was eliminated together with potential associated risks. The summary of the DT program in Girteka at the program initiation phase can be found in Table 2. DT program setup.

Table 2. DT program setup.

\begin{tabular}{|c|c|c|c|c|}
\hline & \multicolumn{3}{|c|}{ Preparation phase } & \\
\hline & & \multicolumn{3}{|c|}{ Program management phase } \\
\hline & WHAT? & HOW? & WHO? & WHEN? \\
\hline Focus on: & $\begin{array}{l}\text { Set the right } \\
\text { foundation to drive } \\
\text { capabilities } \\
\text { fundamental to } \\
\text { Modern Girteka } \\
\text { Logistics Business } \\
\text { and Technology } \\
\text { Strategy. }\end{array}$ & $\begin{array}{l}\text { Choosing SAP solution as a } \\
\text { DT enabler and starting from } \\
\text { the core business process } \\
\text { digitalization and then } \\
\text { continue with the } 2 \text { nd } \\
\text { priority processes }\end{array}$ & $\begin{array}{l}\text { Program and related } \\
\text { project management is } \\
\text { on Girteka side, but all } \\
\text { DT implementation } \\
\text { activities will be done by } \\
\text { experienced external } \\
\text { consults with direct } \\
\text { software Vendor }\end{array}$ & $\begin{array}{l}\text { Program } \\
\text { duration }-5 \\
\text { years }\end{array}$ \\
\hline
\end{tabular}




\begin{tabular}{|l|l|l|l|l|}
\hline & & & $\begin{array}{l}\text { involvement to ensure } \\
\text { quality assurance. }\end{array}$ & \\
\hline $\begin{array}{l}\text { High } \\
\text { level } \\
\text { activities }\end{array}$ & $\begin{array}{l}\text { Vision and values } \\
\text { were set }\end{array}$ & $\begin{array}{l}\text { Implementation of SAP } \\
\text { Transportation Management } \\
\text { on the 1st phase } \\
\text { 2nd phase processes and } \\
\text { sequence not yet defined }\end{array}$ & $\begin{array}{l}\text { Hired professionals to } \\
\text { run the Program and } \\
\text { project and signed } \\
\text { contract with Vendor } \\
\text { and System } \\
\text { Implementation partner }\end{array}$ & $\mathrm{n} / \mathrm{a}$ \\
\hline $\begin{array}{l}\text { Outcomes } \\
\text { for today }\end{array}$ & $\begin{array}{l}\text { Completion rate } \\
\sim 5 \%\end{array}$ & $\begin{array}{l}\text { Fist release of Transportation } \\
\text { Management functionality } \\
\text { went live }\end{array}$ & $\begin{array}{l}\text { For the 2nd phase } \\
\text { realization more system } \\
\text { integrators and Vendors } \\
\text { will be invited }\end{array}$ & $\begin{array}{l}\text { Completion } \\
\text { rate } \neg 20 \%\end{array}$ \\
\hline
\end{tabular}

Having the deep analysis of all gathered information of the DT program in Girteka, study's author for the particular study decided to narrow down the recommendations for DT roadmap by the definition of the optimized way how to map consistently changing short term goals with the business process solution architecture under change and uncertainty circumstances, basically answering on the 2 questions - WHAT? and HOW?

The recommendations for Girteka could be to follow a six phases process described in the Table 3 - Six Phases Process, what is also applicable to any enterprise to be able to find the DT solutions that meet their business need. This approach is in line with the TOGAF® (OpenGoup, 2021) standards what is a proven enterprise architecture methodology used by the world's leading organizations to improve their business efficiency.

Table 3. Six Phases Process

\begin{tabular}{|c|c|l|}
\hline \multicolumn{2}{|c|}{ Phase } & \multicolumn{1}{c|}{ Scope } \\
\hline I & $\begin{array}{c}\text { Business } \\
\text { Strategy }\end{array}$ & $\begin{array}{l}\text { Defines the goals, drivers, metrics, and objectives for success, but not necessarily hot } \\
\text { to get there. } \\
\text { Q: WHAT? PHASE: Preparation }\end{array}$ \\
\hline II & Business Model & $\begin{array}{l}\text { Describes the rationale of how an organization creates, delivers, and captures value in } \\
\text { economic, social, cultural, or other contexts also during the change and uncertainty. } \\
\text { Q: WHAT? HOW? PHASE: Preparation }\end{array}$ \\
\hline III & $\begin{array}{l}\text { Business } \\
\text { Architecture }\end{array}$ & $\begin{array}{l}\text { Provides a bridge between a business model and strategy on one side, and the business } \\
\text { functionality of the enterprise on the other side. It is described by the 3 models: } \\
\text { Business Capability Model, Business Process Model and Business Data Model. } \\
\text { Q: HOW? PHASE: Preparation, Program management }\end{array}$ \\
\hline IV & $\begin{array}{c}\text { IT and Solution } \\
\text { Architecture }\end{array}$ & $\begin{array}{l}\text { Description of the discrete and focused business operation or activity and hot IT } \\
\text { supports that operation by means of products and their interactions. It's described by } 3 \\
\text { models: Solutions Capability Model, Solution Process Model, Solution Data Model. } \\
\text { Q: HOW? PHASE: Preparation, Program management }\end{array}$ \\
\hline V & $\begin{array}{c}\text { Roadmap and } \\
\text { Landscape Plan }\end{array}$ & $\begin{array}{l}\text { A plan for business or technology change, typically operating across multiple } \\
\text { disciplines over multiple years. } \\
\text { Q: HOW? PHASE: Preparation, Program management }\end{array}$ \\
\hline VI & $\begin{array}{c}\text { Solution Design, } \\
\text { Build and Run }\end{array}$ & $\begin{array}{l}\text { Implementing the solution, operating the IT systems, and supporting the users. } \\
\text { Q: HOW? PHASE: Delivery }\end{array}$ \\
\hline
\end{tabular}

Source: OpenGoup (2021)

The DT roadmap for the author's highlighted processes includes the following high-level activities:

- Alignment and calibration of the Vision and Strategy, what includes Phase I and II;

- Business case building and KPI calibration, what includes Phase II and III;

- Transformation roadmap creation and calibration, what includes Phase IV, V and partially VI;

- Business value delivery, what includes Phase VI.

How to ensure the defined vision and chosen realization strategy is still consistent? Usually, alignment on the vision and strategy is done based on the value discovery, value realization and value optimization sessions. 
During the Value Discovery the experience and operational hypothesis for value is developed and during the Value Realization business execution is aligned to hypothesized value, so these activities should be done once unless the Crisis in not dramatically changing the way company operates. However, for the Value Optimization implementation is perfected against plan and external triggers, therefore this activity needs to be executed periodically along the DT program execution.

Business Case creation in early stages is making sense to define the expected outcomes thru the KPIs on the high level, however following the Normalized System Theory (O'Reilly, 2019, O'Reilly, 2020), creation of the Business Case falls under category of ordered complicated activities, when operating with known unknowns, i.e., Business Case is possible only as a snapshot of the current situation but not anyhow reflecting how things will develop considering a lot of moving components and unclear side effects from the DT. Therefore, calibration only possible for certain KPIs what can be adjusted accordingly the momentum.

Business Case can be based or at least include benchmarking analytics against similar companies, but for such analysis it is necessary to have benchmarking database (data from the other companies) what is eventually not possible as such information partially falls under the confidentiality policy. To overcome challenges of data access SAP Value Lifecycle Management (SAP VLM, 2021) solution can be used, because it has anonymized benchmarking data available for such analysis. This tool enables also KPIs calibration over the DT program lifetime.

DT roadmaps need to reflect the way how business values will be achieved by the Digital solutions and organizational changes. Usually for this activity very experienced Enterprise or Business Architects need to be involved due complexity of the comprehensive Digital solutions. Supportive methods and tools can be used for this activity, however initial creation of the roadmap needs to be reviewed, calibrated, and adjusted regularly over the DT program lifetime due to various business events, like change of the business priorities or, like business acquisitions. Usually for the DT roadmaps reference business and IT architecture is used. Reference roadmaps created based on the best-practices of the business processes and related Digital solutions. As close customer decides to adopt best-practices, as more agile and antifragile it becomes, because minimal adjustments for the best-practices are way far cost, time, and resource-efficient comparing to the designing and implementing process from the scratch. The best-practices and reference architecture are provided by the number of software vendors, like SAP in case of Girteka.

Business Value delivery goes into area of the agile project delivery models and will not be described in this study. However, it worth to mention, that nowadays also few software vendors and number of system implementation companies providing their own modifications of the well-known project and program management methodologies specially adjusted accordingly digital product specifics.

To summarize the optimization potential for the roadmap of Girteka DT program focusing on the SAP solutions as the DT enabler, the following Table 4 has been created and reflects the potential SAP tools what can be used to ensure above mentioned DT program optimizations:

Table 4. SAP Tools.

\begin{tabular}{|c|c|c|}
\hline \multicolumn{2}{|r|}{ Phase } & $\begin{array}{ll}\text { SAP Tools } \\
\end{array}$ \\
\hline $\mathbf{I}$ & $\begin{array}{l}\text { Vision and } \\
\text { Strategy }\end{array}$ & $\begin{array}{l}\text { Simulation Game (link), Cards Game (link), Business Value Advisor (link), Customer } \\
\text { Story Finder (link), Practical Adoption Guide (link), Intelligent Enterprise Assessment } \\
\text { (link), SAP Value Lifecycle Manager (link) }\end{array}$ \\
\hline II & $\begin{array}{l}\text { Vision and } \\
\text { Strategy, } \\
\text { Business case }\end{array}$ & 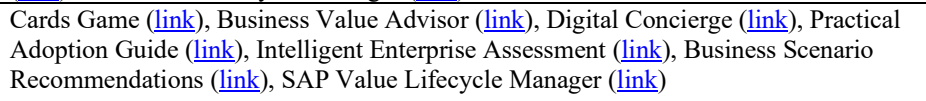 \\
\hline III & Business case & $\begin{array}{l}\text { Simulation Game (link), Cards Game (link), Road Map Explorer (link), Customer Story } \\
\text { Finder (link), Digital Concierge (link), Best Practice Explorer (link), Practical Adoption }\end{array}$ \\
\hline
\end{tabular}




\begin{tabular}{|c|c|c|}
\hline & & $\begin{array}{l}\text { Guide (link), Transformation Content Discovery }(\underline{\text { link }}) \text {, Intelligent Enterprise Assessment } \\
(\underline{\text { link }}) \text {, Transformation Navigator }(\underline{\text { link }}), \text { Business Scenario Recommendations }(\underline{\text { link }}) \text {, SAP } \\
\text { Value Lifecycle Manager (link) }\end{array}$ \\
\hline IV & $\begin{array}{l}\text { Transformation } \\
\text { roadmap }\end{array}$ & 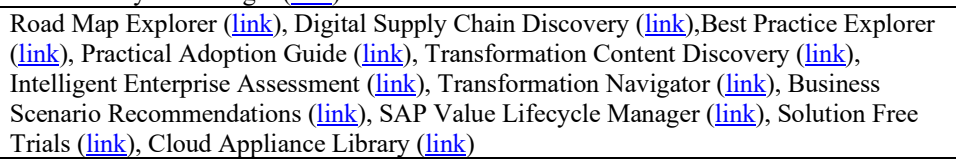 \\
\hline $\mathbf{V}$ & $\begin{array}{c}\text { Transformation } \\
\text { roadmap }\end{array}$ & 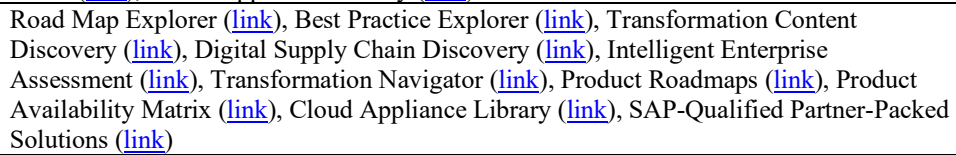 \\
\hline VI & $\begin{array}{l}\text { Transformation } \\
\text { roadmap, } \\
\text { Delivery }\end{array}$ & $\begin{array}{l}\text { Best Practice Explorer (link), Product Availability Matrix (link), Solution Free Trials } \\
\text { (link), Cloud Appliance Library (link), Integration Content Advisor for SAP Cloud } \\
\text { Platform (link), Software Update Manager (link), SAP-Qualified Partner-Packed } \\
\text { Solutions }(\underline{\text { link }), \text { Learning Journeys (link) }}\end{array}$ \\
\hline
\end{tabular}

Source: SAP (2021)

Despite Girteka DT program only at the beginning stage and all initial planning still relevant, the Crisis had and will have impact on the business, what has effect on the DT program priorities. Using modern specialized tools and services provided by the DT advisors, like SAP, could ensure more predictability and agility of the DT program what potentially can lead to antifragility or ar least resiliency.

As the particular topic is very broad there are few aspects need to be highlighted to be considered as the area for the potential future researches, like detailed analysis of DT program + and comparative analysis of it; Rationality of using benchmarking KPIs for a business case creation for DT and potential effect on business KPIs along the DT process, ways to measure it; Use efficiency of specified business architecture creation tools provided by the software vendors; Internal and external DT team competency level requirements, learning curve for digital products among the DT team and expert labor market capacity to support DT.

\section{References}

1. Aghina, W., Ahlbäck, K., De Smet, A., Fahrbach, C., Handscomb, C., Lackey, G., Woxholth, J., Lurie, M., \& Murarka, M. (2018, January 22). Agile organizations - of any size and across industries - have five key elements in common. McKinsey. Retrieved from : https://www.mckinsey.com/business-functions/organization/our-insights/thefive-trademarks-of-agile-organizations

2. Dingsøyr, T., Nerur, S., Balijepally, V., \& Moe, N.B.. (2012). A decade of agile methodologies: Towards explaining agile software development. Journal of Systems and Software, 85(6), 1212-1221.

3. Firk, S., Hanelt, A., Oehmichen, J., \& Wolff, M. (2021). Chief Digital Officers: An Analysis of the Presence of a Centralized Digital Transformation Role. Journal of Management Studies, 58(7), 1800-1831.

4. Girteka Logistics (2021, September 10). About the Girteka. Retrieved form: https://www.girteka.eu/

5. Girteka Logistics (2021, March 17). European Road Transport Challenged To Show Perfection During Covid-19. Retrieved from : https://www.girteka.eu/european-roadtransport-challenged-to-show-perfection-during-covid-19/

6. Gonzalez, L. O., Santomil, P. D., \& Herrera, A. T. (2020). The effect of Enterprise Risk Management on the risk and the performance. European Research on Management and Business Economics, 26(3), 111-120. 
7. Hanelt, A., Bohnsack, R., Marz, D., \& Marante, C.A. (2021). A Systematic Review of the Literature on Digital Transformation: Insights and Implications for Strategy and Organizational Change. Journal of Management Studies, 58(5), 1159-1197.

8. Kunisch, S., Menz, M., \& Langan, R. (2020). Chief Digital Officers: An Exploratory Analysis of Their Emergence, Nature, And Determinants. Long Range Planning, 101999.

9. Magyar, J. (2020, May 14). Creating a New Normal for Truckers. SAP. Retrieved from : https://news.sap.com/2020/05/girteka-truckers-new-normal/

10. Magyar, J. (2020, May 12). Truckers Discover New Purpose Delivering EssentialsDuring the Pandemic. Forbes. Retrieved from : https://www.forbes.com/sites/sap/2020/05/12/truckers-discover-newpurposedeliveringessentials-during-pandemic/?sh $=510 \mathrm{ede} 4058 \mathrm{bb}$

11. McKinsey (2020, August 20). The Digital-Led Recovery from COVID-19: Five Questions for CEOs. Retrieved from: https://www.mckinsey.com/businessfunctions/mckinsey-digital/our-insights/the-digital-led-recovery-from-covid-19-fivequestions-for-ceos\#

12. O'Reilly, B. (2019). No more snake oil: Architecting agility through antifragility. Procedia Computer Science, 151, 884-890.

13. Ramezani, J., \& Camarinha-Matos, L. M. (2020). Approaches for resilience and antifragility in collaborative business ecosystems. Technological Forecasting and Social Change, 151.

14. O'Reilly, B. M. (2020). An introduction to residuality theory: Software design heuristics for complex systems. Procedia Computer Science, 170, 875-880.

15. SAP (2021, September 10). SAP Transportation Management. Retrieved from: https://www .sap. com/products/transportation-logistics.html

16. SAP VLM (2021, September 10). SAP Value Lifecycle Management. Retrieved from : https://vlm.cfapps.eu10.hana.ondemand.com/index.html\#/home

17. Sharma, P., Leung, T. Y., Kingshott, R. P. J., Davcik, N. S., \& Cardinali, S. (2020). Managing uncertainty during a global pandemic: An international business perspective. Journal of Business Research, 116, 188-192.

18. Singh, A., Klarner, P., \& Hess, T. (2020). How do chief digital officers pursue digital transformation activities? The role of organization design parameters. Long Range Planning, 53(3), 101890.

19. The Open Group (2021, September 15). The TOFAG Standard, Version 9.2 Overview. Retrieved from : TOFAG. https://www.opengroup.org/togaf

20. Verhoef, P. C., Broekhuizen, T., Bart, Y., Bhattacharya, A., Qi Dong, J., Fabian, N. \& Haenlein, M. (2021). Digital transformation: A multidisciplinary reflection and research agenda. Journal of Business Research, 122, 889-901.

21. Wessel, L, Baiyere, A., Ologeanu-Taddei, R., Cha, J., \& Blegind Jensen, T. (2021). Unpacking the Difference Between Digital Transformation and IT-Enabled Organizational Transformation. Journal of the Association for Information Systems, 22(1), 102-129. 